\title{
Assessing the potential for local action to achieve EU limit values
}

\author{
J. H. Barnes, T. J. Chatterton, E. T. Hayes, \\ J. W. S. Longhurst \& A. O. Olowoporoku \\ Air Quality Management Resource Centre, \\ University of the West of England, Bristol, UK
}

\begin{abstract}
Despite 14 years of UK Local Air Quality Management (LAQM), ambient $\mathrm{NO}_{2}$ concentrations have not decreased as expected. Although $\mathrm{NO}_{2}$ concentrations decreased from 1996 to 2002-4, this trend has subsequently levelled off. The UK Government has failed to meet European Union (EU) limit values for $\mathrm{NO}_{2}$ and $\mathrm{PM}_{10}$ and risks incurring fines of $\sim £ 300 \mathrm{~m}$. The number of local authorities $(60 \%)$ having declared Air Quality Management Areas (AQMAs), primarily for trafficrelated pollutants $\left(\mathrm{NO}_{2}\right.$ and $\left.\mathrm{PM}_{10}\right)$, has grown steadily since 2001, and despite the production of local Air Quality Action Plans (AQAPs) there have been no traffic-related AQMA revocations solely on the basis of their implementation. The UK Air Quality Strategies (1997-2007) have focussed on emission reduction technologies to reduce overall pollutant concentrations, whilst LAQM targets specific local hotspots often through air quality measures in Local Transport Plans. The failure of this system to achieve necessary $\mathrm{NO}_{2}$ reductions has been attributed in part to a reliance of national policy on Euro vehicle standards, without significant endeavour to reduce road traffic growth. Locally, deficiencies in funding, interdepartmental communication, political will and public awareness, have been criticised for hindering action plan measures. The UK Government's localism agenda threatens to reduce the top-down governance of LAQM whilst also introducing the potential for EU fines to be passed to local authorities where limit values are exceeded. At the same time, the UK Government has outlined changes that will put more emphasis on the development of local measures to achieve EU limit values. This paper discusses
\end{abstract}


the potential for local action to achieve the limit values and concludes that further work is necessary at a national level to assist local authorities in this aim. Keywords: local air quality management, air quality action plans, $\mathrm{NOx}, \mathrm{NO}_{2}$, $P M_{10}$, EU limit values, nitrogen dioxide, particles, air pollution, localism.

\section{Introduction}

Part IV of the UK Environment Act 1995 (HM Government [1]) established a range of roles and responsibilities for both national and local government with respect to air quality management. The Act was a pre-emptive approach to address the 1996 EU Framework Directive (Council Directive 96/62/EC) (European Commission [2]) (subsequently replaced by the Council Directive on Ambient Air Quality and Cleaner Air for Europe (2008/50/EC) (European Commission [3])), the daughter directives of which imposed limit values for specific pollutants to be achieved by Members States. The Environment Act 1995 and the subsequent 1997 National Air Quality Strategy (Department of the Environment [4]) recognised the impact of traffic emissions on ambient air quality, and established national air quality objectives for the seven pollutants of concern $\left(\mathrm{NO}_{2}, \mathrm{PM}_{10}, \mathrm{SO}_{2}, \mathrm{CO}\right.$, benzene, 1,3-butadiene and lead) which reflected the EU limit values. The Strategy also divided responsibility for managing air quality between central government, which was expected to carry the main burden of the air quality improvements by reducing pollutant concentrations across all relevant locations, and local authorities, whose focus was on tackling residual local pollution hotspots (Longhurst et al. [5]). Little was known at that time about the extent or magnitude of these hotspots, which were assumed to be localised and limited to major urban areas (Chatterton et al. [6]). The experience of local authorities over the last 14 years, however, has found that exceedences of the national air quality objectives (and EU limit values) for $\mathrm{NO}_{2}$ and $\mathrm{PM}_{10}$ are common and widespread, and tend to occur wherever high volume and/or congested traffic and residences coincide.

There are currently $244(60 \%)$ local authorities in the UK with AQMAs, primarily for $\mathrm{NO}_{2}$ and $\mathrm{PM}_{10}$ from traffic sources (Defra [7]), where local authorities are required to work towards reducing ambient concentrations of these pollutants to meet the air quality objectives through the production and implementation of AQAPs. However, to date there is no evidence of any trafficrelated AQMAs having been revoked solely on the basis of their implementation (Longhurst et al. [5]). Similarly, national government is also in the process of preparing annual Air Quality Plans for the European Commission in respect of its failure to meet EU limit values for $\mathrm{NO}_{2}$ and $\mathrm{PM}_{10}$ by the specified deadlines. The UK is currently exceeding the $\mathrm{NO}_{2}$ annual mean limit values + Margin of Tolerance (MOT) $\left(48 \mu \mathrm{g} / \mathrm{m}^{3}\right)$ in 40 out of 43 zones and agglomerations and are intending to submit a time extension notification and Air Quality Plan in September 2011 (Defra [8]). Exceedences of the $\mathrm{PM}_{10}$ limit values + MOT are limited to Greater London and a time extension has recently been awarded to June 2011 (European Commission [9]). Failure to comply with the EU limit 
values may incur significant financial penalties estimated to be in the region of $£ 300$ million (ENDS [10]).

\section{Why are limit values being breached?}

\subsection{Emission factors/Euro standards}

The national strategy to reduce concentrations of $\mathrm{NOx}$ and $\mathrm{NO}_{2}$ has, to date, focused predominantly on emission reduction strategies, primarily relying on the integration of Euro standard vehicles into the national fleet, often in advance of formal compliance dates. However, recent work suggests that this reliance may have been overoptimistic (Carslaw et al. [11]). Although trends in ambient NOx and $\mathrm{NO}_{2}$ in the UK decreased from $\sim 1996$ to 2002-4, from 2004 to 2009 these trends have levelled off. Furthermore, whilst total NOx emissions may have decreased, NOx emitted as primary $\mathrm{NO}_{2}$ from motor vehicles has increased from $5-7 \%$ to $15-16 \%$ over the same period (Carslaw et al. [11]). Data from roadside remote sensing detectors has suggested that, under typical urban-type driving conditions, emissions are higher than those recorded in the National Atmospheric Emissions Inventory (NAEI). In particular, NOx emissions for the later Euro standard diesel and light duty vehicle classes have not fallen as predicted and instead have remained relatively stable over the last 15 years (Carslaw et al. [11]). Also, the slight decrease in NOx from petrol emissions has, to some extent, been offset by a significant increase in the number of diesel vehicles on the road (partly due to government policies such as adjustments to vehicle excise duty that have encouraged 'dieselisation' for climate change reasons). There may also be further underestimations regarding the rate of vehicle renewal, meaning that there are potentially older, dirtier vehicles on the road than previously anticipated.

These flawed NAEI emission factors have also been used by the Department for Food and Rural Affairs (Defra) to derive future year projection factors for roadside $\mathrm{NO}_{2}$, which have in turn been used by local authorities to predict when local roadside $\mathrm{NO}_{2}$ concentrations are likely to fall below air quality objective levels, and by developers undertaking air quality assessments to indicate the likely future impact of their developments. Although the validity of the emission factors had already been called into question as forecast concentrations failed to reflect monitoring trends (Institute for Air Quality Management [12]), this revelation is likely to have repercussions for local air quality where AQAPs may fall short of expectations and developments that may not otherwise have been approved on air quality grounds have been granted planning permission.

\subsection{Lack of interdepartmental responsibility/political will}

One of the main criticisms voiced in the recent UK Environmental Audit Committee report on air quality was the lack of interdepartmental communication in central government regarding the importance of air quality (Environmental Audit Committee [13]). Despite the clear cost-benefit case and 
obvious need for transport policy to play its part in reducing the effects of traffic emissions, air pollution does not appear to be a significant political priority. This is illustrated by the Transport Minister's response to the UK's failure to meet the EU limit value for $\mathrm{NO}_{2}$, in which he is reported to be querying with Defra and the EU the validity of the limit value which he claims has "perverse side effects" and will require "disproportionate effort" to achieve (Air Quality Bulletin [14]). The fact that 'improving air quality' has been demoted from a "shared priority" with 'tackling congestion', delivering accessibility' and 'ensuring safer roads' in the second round of Local Transport Plans (LTP) to a secondary consideration in Round 3, again conveys a lack of political recognition. (Though evidence from Round 2 strongly suggested that "shared priority did not mean equal priority" (Olowoporoku et al. [15]).) Even where central policy guidance has included air quality (e.g. Planning Policy Statement (PPS) 23 (Office of the Deputy Prime Minister [16]), which established air quality as a material planning concern, and Public Service Agreement (PSA) 28 (HM Treasury [17]), which gave the Department for Transport and Defra joint ownership of the air quality indicators for $\mathrm{NO}_{2}$ and $\mathrm{PM}_{10}$ ), air quality still fails to receive adequate recognition.

A lack of recognition of the importance of air quality at a national level is reflected at the local level in terms of political priorities. Environmental Health Officers (EHOs) struggle to raise awareness of local air quality and the lack of perception of the relative importance of air quality restricts their ability to negotiate action plan measures and air quality assessments with transport and planning departments, particularly where there are conflicting priorities regarding economic development promoted by central government departments (Carmichael and Lambert [18]). At a local level there may also be the limitations of local politics with the potential for vested interests and short-termism and a lack of political leadership and courage to pursue more novel and sustainable approaches to economic development.

\subsection{Lack of funding}

Air quality management, including monitoring and modelling, is an expensive operation, which is significantly underfunded due in part to its low political status. Limited air quality grants are available annually from Defra but are always oversubscribed $-£ 2 \mathrm{~m}$ has been made available for 2011/12 to assist the 244 local authorities with one or more AQMAs to implement their AQAP measures. In previous years the Defra grant has been ring-fenced for air quality purposes, however this "limitation" has been removed in 2011 to allow local authorities more flexibility to manage their own priorities, given the substantial cuts in public funding that local authorities are currently facing.

For those local authorities that are able to link their AQAPs with LTPs, measures to improve local air quality can also be funded through this means. However, the reductions in LTP funding too, together with the deprioritisation of air quality in Round 3 of the LTP process, will inevitably mean difficulties in ensuring air quality improvements are properly considered.

There are also mechanisms to obtain funding from developers to offset the air quality impacts of developments through the planning process under section 106 
agreements. These funds are typically acquired at the planning approval stage, however, political pressures to drive economic development will likely restrict any potential obstruction that may be seen to limit inward investment.

\subsection{Scientific complexities}

\subsubsection{Health}

Part of the reason for the lack of political support for air quality issues stems from a lack of understanding. Despite the publication of reports from the Committee on the Medical Effects of Air Pollution (COMEAP) expounding the health impacts of human exposure to pollutants, it may be difficult for nonexperts to realise the significance of " 200,000 premature deaths" or an "average two years life lost" (COMEAP [19]). Added to that, these figures are often couched in terms of uncertainty as the nature of air pollution means that, unlike road traffic accidents for example, it is not identifiable as a direct physiological cause of death, but as a contributory factor in reducing people's overall lifeexpectancy, along with many other contributory, and potentially inter-related, lifestyle factors such as diet and exercise patterns. Such reports are also usually pollutant specific, whereas public exposure is not to a single pollutant exclusively but to a range of interacting and potentially exacerbating pollutants. It is also unclear whether the separately reported health effects of short-term and long-term exposure to pollutants are additive or exclusive, what the specific or cumulative effects of fine and ultrafine particles are, or the effects of pollutants on morbidity as well as mortality (COMEAP [19]).

\subsubsection{Monitoring and modelling}

The assessment of local air quality depends on the accurate monitoring and modelling of pollutant concentrations. Unfortunately the physicochemical properties of air pollution are complex and significant scientific uncertainties remain. In order to be comparable with the health-based air quality objectives and limit values monitoring methods should represent public exposure to the pollutants in question. The technical difficulties of measuring pollutants over specified averaging periods, whilst accounting for the effects of meteorology, technology and human error, means that there is inevitably a degree of uncertainty in the monitoring results. Indeed the most common method of monitoring $\mathrm{NO}_{2}$ in the UK, using passive diffusion tubes, is subject to $\pm 25 \%$ uncertainty (Defra [20]). Although precision and accuracy are controlled to some extent through the use of quality assurance and quality control procedures and techniques, there is still an acceptance that there will be a certain level of uncertainty inherent in the monitoring results.

Dispersion modelling too has inherent error, as a simplification of reality with limited inputs and various assumptions made in the absence of complete and accurate data. Models are also often verified and adjusted against monitoring data and so are therefore only as accurate as the monitoring data against which the results have been assessed.

This uncertainty in assessment data is difficult to convey to non-air quality specialists, e.g. developers, land use and transport planners and even the general 
public, which can hamper political acceptance of air quality problems and the integration of air quality into LTPs and local planning guidance.

\section{Where next for local air quality management?}

\subsection{National agenda}

There has been a move to reduce the bureaucratic burden on local authorities under the Government's 'Freedoms and Flexibilities' agenda since the publication of the Local Government Act 2000 (section 6) (HM Government [21]). However, the current UK Government is making this a political imperative though the 'localism' agenda.

The Localism Bill (HM Government [22]), introduced to the UK Parliament in December 2010, included a clause in Part 2 enabling the transfer of responsibility for EU penalties to local authorities, however the precise detail is subject to Parliamentary approval. This potential for local authorities to find themselves financially liable for breaches of the EU limit values has been described as "unfair" by local authorities whose legal remit was to develop AQAPs "in pursuit" of achieving the national air quality objectives and with no direct responsibility to the EU (Local Government Association [23]).

While Defra may be keen to share responsibility for meeting the EU limit values with local authorities, they also maintain that they will be available to support them. Although there are not yet any firm guidelines on how the LAQM framework is likely to change, some of the possibilities have been outlined (Air Quality Bulletin [24]), including:

- Consolidating EU and national air quality objectives.

- Sharing information on compliance assessment with local authorities.

- Including local AQAP measures in national Air Quality Plans.

- Continuing local screening for hotspots.

- Introducing proportionate screening and reporting.

\subsection{Local implications}

Local authorities in the UK are currently under significant pressure to 'do more with less' as they face an estimated $£ 6.5$ bn public funding cut over the next two years (Local Government Association [25]). This will have significant consequences for air quality management, which is already marginalised by other financial and political priorities. The removal of ring-fencing from air quality grants will further reduce the ability of EHOs to safeguard future monitoring and to provide resources for the implementation of AQAPs. As shrinking budgets force redundancies in local government, EHOs will also find themselves stretched to cover additional duties and having to deal with new priorities.

One of the implications of the current UK Government's move towards localism is that public health will be devolved from regional Public Health Authorities to upper-level councils. For unitary or metropolitan councils this will 
put LAQM and public health within the same local government body, which could benefit communication between EHOs and public health officers. For those local authorities that operate in a two-tier municipality (i.e. district and county councils) public health will reside with the county council, whilst environmental health responsibilities will continue to sit at a lower level, district council. This will create the same inter-organisational divide between air quality and public health as exists between air quality and transport planning, where district level EHOs have experienced difficulties in raising the profile of air quality (Olowoporoku et al. [15]).

What is not clear is what local authorities will choose to prioritise under localism. Communities and neighbourhoods are likely to be given greater rights and remit to influence local politics and to drive the local political agenda, however if this is the case the implications for air quality are not promising. At present, outside of London, the public could be forgiven for assuming air quality is good, given the absence of the dense smogs of 60 years ago. Public admission of air quality as a "problem" may also be clouded by a reluctance to admit complicity, as a nation of motorists, or ownership of the solution in the absence of alternative modes of transport or requirements to travel.

There are also legal responsibilities incumbent on local authorities under the Environment Act 1995, namely to declare AQMAs where air quality objectives are being breached, and subsequently to prepare Further Assessments and AQAPs to investigate and work towards meeting the objectives. Unless the Act is amended by Parliament, local authorities will still be required to meet these obligations.

The decentralisation of power and devolution to local authorities could be seen as potentially damaging for the future of LAQM, which until now has maintained its, albeit limited, profile to a large degree due to the statutory annual reporting requirements. While the focus on diagnosis and reporting has itself been criticised as detracting from the more challenging need to manage air quality (In-House Policy Consultants [26]), there is a risk that if the statutory responsibility is removed, and local authorities are left to devise their own priorities, then air quality will come second to other more tangible or visible local needs. On the other hand, it may (optimistically) be argued that without the conflicting priorities of disconnected central government departments, local authorities may be able to manage air quality as part of a more holistic, locally sustainable approach to development.

\section{Conclusions}

When first devised, the role of LAQM was undervalued by government as a supplementary role in achieving the EU limit values, and has suffered a lack of political support because of this early misconception. Over the following 14 years however, local authorities have risen to the challenge of LAQM and have excelled at diagnosing air quality problems. Their ability to successfully devise and implement AQAPs subsequently, however, has been constrained by other political priorities and a seeming lack of appreciation of the significance of air 
quality issues by departments outside of environmental protection, both at a local and a national level.

In addition to identifying the difficulties that UK local authorities have faced to date in managing local air quality, this paper has indicated that the forthcoming localism agenda is unlikely to improve this situation and may have the potential to reduce local authorities' ability to meet national air quality objectives and, therefore, EU limit values.

At the same time, the failure of the UK Government to achieve EU limit values has finally brought to Defra's attention the value of local AQAPs. What remains to be seen is how the government propose to ensure that they can rely on effective local action in the event of devolved power and moreover how they can best assist and support local authorities to bring these plans to fruition.

\section{References}

[1] HM Government, Environment Act 1995, The Stationery Office, London, 1995.

[2] European Commission, Council Directive 96/62/EC of 27 September 1996 on ambient air quality assessment and management. 21/11/1996. Official Journal L 296, 55-63, 1996.

[3] European Commission, Council Directive 2008/50/EC of 21May 2008 on ambient air quality and cleaner air for Europe. 11/6/2008. Official Journal L $152,1-44,2008$.

[4] Department of the Environment, The United Kingdom National Air Quality Strategy, 1997.

[5] Longhurst, J.W.S., Irwin, J.G., Chatterton, T., Hayes, E.T. \& Leksmono, N.S., The Development of Effects Based Air Quality Management Regimes, Atmospheric Environment, 43(1) 64-78, 2009.

[6] Chatterton, T.J., Longhurst, J.W.S., Leksmono, N.S., Hayes, E.T. \& Symons, J.K., Ten years of Local Air Quality Management experience in the UK: An analysis of the process, Clean Air and Environmental Quality, 41(4): 26-31, 2007.

[7] Defra, List of Local Authorities with AQMAs, http://aqma.defra.gov.uk/ list.php [Accessed 31/5/11].

[8] Defra, Air Pollution in the UK 2009- Edition B, 2010.

[9] European Commission, C(2011) 1592 final, Commission Decision of 11.3.2011 on the notification by the United Kingdom of Great Britain and Northern Ireland of an exemption from the obligation to apply the daily limit value for $\mathrm{PM}_{10}$ in zones UK0001 and UK(GIB) 2011.

[10] ENDS Report, Government seeks time to meet air quality limits, 409, p. 46, February 2009.

[11] Carslaw, D., Beevers, S. Westmoreland, E. Williams, M. Tate, J. Murrells, T. Stedman, J. Li, Y., Grice, S., Kent, A. and I. Tsagatakis (2011). Trends in $\mathrm{NOx}$ and $\mathrm{NO}_{2}$ emissions and ambient measurements in the UK. Version: 3rd March 2011. Draft for Comment. 
[12] Institute for Air Quality Management, Report on the Meeting on Future $\mathrm{NO}_{2}$ Concentrations -1 July 2010, http://www.iaqm.co.uk/text/resources/ report_on_no2.pdf [Accessed 1/6/11].

[13] Environmental Audit Committee, Air Quality, Fifth Report of Session 2009-10, Vol. 1, HC 229-I, The Stationery Office, London, 22 March 2010.

[14] Air Quality Bulletin, Government lobbies on $\mathrm{NO}_{2}, 60$, p.1, April 2011.

[15] Olowoporoku, A.O., Hayes, E.T., Leksmono, N. S., Longhurst, J.W.S. and Parkhurst, G., A longitudinal study of the links between Local Air Quality Management and Local Transport planning policy processes in England. Journal of Environment Planning and Management, 53(3), 385-403, 2010.

[16] Office of the Deputy Prime Minister, Planning Policy Statement 23: Planning and Pollution Control. Annex 1: Pollution Control, Air and Water Quality, 2004.

[17] HM Treasury, PSA Delivery Agreement 28: Secure a healthy natural environment for today and the future, 2007.

[18] Carmichael, L. and Lambert, C., Governance, knowledge and sustainability: the implementation of EU directives on air quality in Southampton, Local Environment, 16: 2, 181-191, 2011.

[19] COMEAP, The Mortality Effects of Long-Term Exposure to Particulate Air Pollution in the United Kingdom, Health Protection Agency, ISBN 978-085951-685-3, 2010.

[20] Defra, Part IV of the Environment Act 1995 [Environment (Northern Ireland) Order 2002 Part III] Local Air Quality Management Technical Guidance LAQM.TG(09), 2009.

[21] HM Government, Local Government Act 2000, The Stationery Office, London, 2000.

[22] HM Government, Localism Bill, December 2010.

[23] Local Government Association, Localism Bill - EU Fines, LGA Briefing, April 2011.

[24] Air Quality Bulletin, Defra hints on future changes, 60, p.5, April 2011.

[25] Local Government Association, Funding settlement 'will lead to cuts in services', First Online, December 2010, http://www.lga.gov.uk/lga/core/ page.do?pageId=15662390 [Accessed 1/6/2011].

[26] In-House Policy Consultants, Review of Local Air Quality Management, A report to Defra and the devolved administrations, March 2010. 